\title{
Comparison of Three Methods for Determining the Prey Preference of the Muricid Snail Reishia clavigera
}

\author{
Morihiko Tomatsuri and Koetsu Kon \\ Shimoda Marine Research Center, University of Tsukuba, 5-10-1 Shimoda, Shizuoka 415-0025, Japan \\ Correspondence should be addressed to Morihiko Tomatsuri; toma@shimoda.tsukuba.ac.jp
}

Received 16 December 2014; Revised 24 April 2015; Accepted 28 April 2015

Academic Editor: Evgeny Pakhomov

Copyright (C) 2015 M. Tomatsuri and K. Kon. This is an open access article distributed under the Creative Commons Attribution License, which permits unrestricted use, distribution, and reproduction in any medium, provided the original work is properly cited.

\begin{abstract}
We propose an appropriate method for investigating the prey preferences of the muricid snail Reishia clavigera (Küster, 1860) with limited collection of live prey. We compared 3 methods for examining the prey preference. The first was a predation experiment, conducted with dead prey instead of live prey. The second was a prey choice test using a few preys. In this experiment, both live and dead prey were used. The last method was a stable isotope analysis of $R$. clavigera and its putative prey items. Using live prey, bivalves were the most preferred prey, but goose barnacle was the most preferred prey species in experiments using dead prey. The carbon and nitrogen stable isotope analysis supported the live prey experiment. Since $R$. clavigera prefer preying on live prey but will scavenge or cannibalize when no other food is available in natural habitats, experimental methods using dead prey are not suitable for investigating its prey preferences. Considering the damage to natural habitats, the prey choice test is ecologically benign. Taken together, our findings suggested the prey choice test is the most appropriate method of identifying the prey preferences of muricid snails when large numbers of live preys are difficult to collect.
\end{abstract}

\section{Introduction}

Predation is widely considered an important process that regulates the spatial distribution and population dynamics of animals, which in turn determines the community structure of various ecosystems. For example, in Kasumigaura Lake located in central Japan, the invasive carnivorous fish Ictalurus punctatus (Rafinesque, 1818) can directly reduce species diversity through predation on various other species $[1,2]$. In such cases, nonselective predation leads to the collapse of prey populations. However, predation can also have an opposite effect. The starfish Pisaster ochraceus (Brandt, 1835) is the top predator in the intertidal rocky shores of the Northwest Pacific Coast and can maintain species diversity via selective consumption that regulates the abundances of competing mussel species [3]. In such cases, predation indirectly facilitates species that are inferior competitors. Thus, prey preference can be an important determinant of community structures in many aquatic ecosystems.

The muricid snail Reishia clavigera (Küster, 1860) is a carnivorous predator in the intertidal rocky shores throughout temperate and tropical regions of the Western Pacific, including Japan. Species belonging to Muricidae have varied diets (including barnacles, limpets, and bivalves) with each species having specific prey preferences [4]. They are thought to be important predators that determine the community structure in the intertidal rocky shores. Their prey preferences have been investigated using predation experiments to determine the amounts of various prey items consumed [5]. Such predation experiments have been performed using various carnivorous marine predators $[6,7]$, but they often require large quantities of live prey. Hence, performing such predation experiments on $R$. clavigera might be difficult due to constraints on obtaining prey. Their prey includes fragile barnacle species (e.g., Tetraclita japonica (Pilsbry, 1916)), and collecting many intact individuals from the rocky substrate on which they occur is difficult. Due to this constraint, another more appropriate method is required to determine the prey preference of $R$. clavigera.

One such method is a predation experiment using dead instead of live prey. Obviously using live prey is the best way to determine the prey preferences of carnivorous species. 
Nevertheless, this method might be the next best option where the supply of live prey is restricted. A second possible alternative is a prey choice test. Similar methods are often used in habitat choice experiments [8,9], and such methods could be effective if modified to determine the prey choice instead of habitat selection. Although this method does not assess predation directory, but rather only preference for prey as determined by orientation, it can be performed using a small quantity of live prey. Carbon and nitrogen stable isotope analyses have recently been applied to determine the rates at which various prey sources are consumed [10]. However, the rate of consumption does not always reflect prey preference, because it could depend on prey abundance in natural habitats. However, in combination with data on the abundance of prey species in a predator's habitat, this technique might prove valuable.

Accordingly, we performed (1) a predation experiment, (2) prey choice test, and (3) carbon and nitrogen stable isotope analyses and compared the results to determine the most appropriate method of determining the prey preferences of $R$. clavigera.

\section{Materials and Methods}

2.1. Sample Collection and Site Description. Samples were collected from three intertidal rocky shores (Nabeta, Shirahama, and Suzaki) on the southern Izu Peninsula, Shizuoka, Japan. All the sites experience semidiurnal tides with a tidal range of $0-1.8 \mathrm{~m}$ and have an annual water temperature ranging from $13^{\circ} \mathrm{C}$ to $26^{\circ} \mathrm{C}$. Nabeta is a flat rocky shore located in the inner part of a small bay with a limited swash zone $\left(34^{\circ} 40^{\prime} \mathrm{N}, 138^{\circ} 56^{\prime} \mathrm{E}\right)$. Suzaki is situated in a jutting lumpy shore, with a wide swash zone $\left(34^{\circ} 39^{\prime} \mathrm{N}, 138^{\circ} 57^{\prime} \mathrm{E}\right)$. Shirahama is a relatively isolated rocky shore surrounded by a sandy beach $\left(34^{\circ} 41^{\prime} \mathrm{N}, 138^{\circ} 58^{\prime} \mathrm{E}\right)$.

We collected $R$. clavigera and three putative prey species [5]: T. clavigera, goose barnacle Capitulum mitella (Linnaeus, 1758), and the Mytilidae bivalves Septifer virgatus (Wiegmann, 1837). We used another Mytilidae species Arcuatula senhousia (Benson in Cantor, 1842) because S. virgatus was absent in Suzaki. To overcome the effect of ontogenetic change in prey preference, we collected appropriately similarsized individuals of each species: the adult predatory $R$. clavigera (shell length $>2.5 \mathrm{~cm}$ ), C. mitella (height $>3.0 \mathrm{~cm}$ ), T. japonica (width $>3.0 \mathrm{~cm}$ ), and Mytilidaespecies (height, $>$ $3.0 \mathrm{~cm}$ ). All the species were collected and investigated before the spawning season.

2.2. Species Composition. To evaluate the composition of prey species at each site, we conducted observations in May and June 2013. We randomly placed a $1 \mathrm{~m} \times 1 \mathrm{~m}$ quadrat in the upper intertidal zone and counted the number of individuals of each species. We used 10 replicates at each site. The relative abundance of each prey species was quantified as the number of prey individuals per $R$. clavigera individuals.

2.3. Predation Experiment. We measured the rate at which $R$. clavigera preyed on each prey species. At each study site,

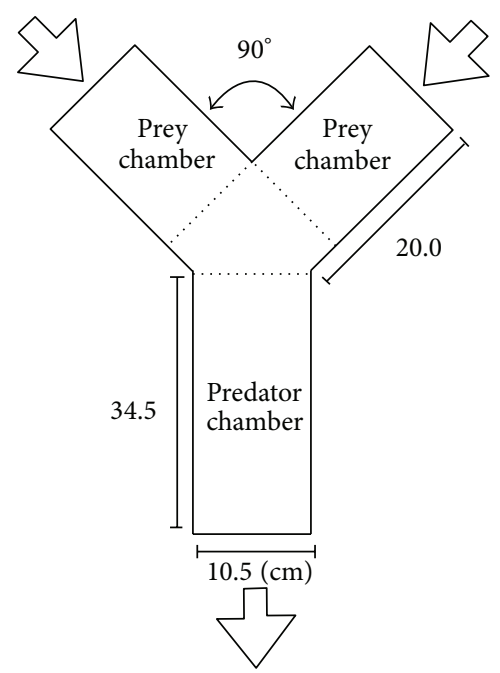

FIGURE 1: Schematic diagram of the $Y$-maze. Open arrows indicate the direction of water flow. Dimensions are expressed in centimeters. Components are not drawn to scale.

90 R. clavigera individuals and 60 dead individuals of each prey were collected in June to August 2013. Before the experiment, the predator was placed in flowing seawater for 1 month, under starvation conditions, and the prey species were stored at $-60^{\circ} \mathrm{C}$. We used 10 perforated plastic cups (height, $4 \mathrm{~cm}$; diameter, $8 \mathrm{~cm}$ ) for the experiment. The cups were submerged in a plastic tank $(50 \mathrm{~cm} \times 30 \mathrm{~cm} \times$ $10 \mathrm{~cm}$ ) containing flowing seawater; the experimental design allowed a continual flow of water but prevented the escape of experimental subjects. We placed 1 predatory $R$. clavigera and 2 prey items ( 1 individual from each of 2 different species by using all prey pair combinations at each study site) into each cup and recorded the species preyed on after 2 days. We replicated the experiment for each prey pair combination 30 times for each site.

2.4. Prey Choice Test. We observed the rate at which $R$. clavigera chose each prey species to estimate the effect on choice preference of chemical cues originating from prey items. Besides conducting the experiment using live prey, we performed another choice test by using dead preys, in order to compare the results with the dead prey predation test. At each study site, $50 \mathrm{R}$. clavigera individuals and 10 live and 10 dead individuals of each prey species were collected from June to August 2013. We placed the prey individuals in flowing natural seawater. The predators were starved for 1 month. Live prey could consume particulate organic matter contained in the flowing natural seawater. We used a plastic $Y$-maze (with seawater flowing at $1.5 \mathrm{~L}$ per minute from the top two branches to the lower end). We placed 2 perforated plastic bottles (height, $9.0 \mathrm{~cm}$; diameter, $7.5 \mathrm{~cm}$ ) that had inflow and outflow holes (diameter, $1 \mathrm{~cm}$ ) sidewise at the ends of the top branches (Figure 1). To perform the experiment we placed 10 individuals from one prey species into one bottle and 10 individuals from a different prey species in the other bottle and placed one $R$. clavigera individual in 
TABLE 1: Ranked prey preferences of the muricid snail Reishia clavigera from experiments using dead prey and prey choice tests using dead and live prey in Nabeta, Shirahama, and Suzaki, the southern Izu Peninsula, Shizuoka, Japan $(n=30$ in predation experiment and prey choice test using dead prey, $n=20$ in prey choice test using live prey). Cm, Tj, Sv, and as indicate Capitulum mitella, Tetraclita japonica, S. virgatus, and $A$. senhousia, respectively.

\begin{tabular}{|c|c|c|c|c|c|c|c|c|c|}
\hline \multirow{3}{*}{$\begin{array}{l}\text { Prey conditions } \\
\text { Rank } \backslash \text { sites }\end{array}$} & \multicolumn{3}{|c|}{ Predation experiment } & \multicolumn{6}{|c|}{ Prey choice test } \\
\hline & & Dead & & & Dead & & & Live & \\
\hline & Nabeta & Shirahama & Suzaki & Nabeta & Shirahama & Suzaki & Nabeta & Shirahama & Suzaki \\
\hline 1 & $\mathrm{Cm}$ & $\mathrm{Cm}, \mathrm{Tj}$ & $\mathrm{Cm}$ & $\mathrm{Cm}$ & $\mathrm{Cm}, \mathrm{Tj}$ & $\mathrm{Cm}, \mathrm{Tj}$ & Sv & $\mathrm{Sv}, \mathrm{Tj}$ & As \\
\hline 2 & $\mathrm{Tj}$ & - & As & $\mathrm{Tj}$ & - & - & $\mathrm{Cm}$ & - & $\mathrm{Tj}$ \\
\hline 3 & Sv & Sv & $\mathrm{Tj}$ & Sv & Sv & As & $\mathrm{Tj}$ & $\mathrm{Cm}$ & $\mathrm{Cm}$ \\
\hline
\end{tabular}

the stem of the $Y$ at a distance of $15 \mathrm{~cm}$ from the junction with the branch. The seawater flowing through the bottles to $R$. clavigera contained prey chemical cues. We then recorded which branch of the tunnel (and prey species) R. clavigera preferred. We conducted 30 trials by using live prey and 20 trials by using dead prey for each prey pair combination at each study site. In each trial, we assigned the bottles with each prey to different sides of the junction. Between the trials, the experimental device was cleaned with a sponge to prevent cross contamination of chemical cues.

2.5. Stable Isotope Analysis. To quantify the contribution of each prey item to the diet of $R$. clavigera at each site, we analyzed the carbon and nitrogen stable isotope ratios of $R$. clavigera and its putative food items (C. mitella, T. japonica, $S$. virgatus, and $A$. senhousia). We randomly collected 5 individuals per species from Nabeta in September 2013 and from Shirahama and Suzaki in May 2014. Muscle tissue samples were obtained from the body of each individual and washed with distilled water. The samples were dried at $60^{\circ} \mathrm{C}$ for $24 \mathrm{~h}$ until a constant weight was achieved and then ground to a fine powder. Samples were transferred into clean tin capsules and introduced into an elemental analyzer connected online to an isotope mass spectrometer (ThermoElectron, Flash EA, Conflo III, DELTA plus XP). Isotope values were expressed in $\delta$-notation as \%o differences from the international standards (Vienna Pee Dee Belemnite for carbon; atmospheric $\mathrm{N}_{2}$ for nitrogen):

$$
\delta X(\%)=\left\{\left(\frac{R_{\text {sample }}}{R_{\text {standard }}}\right)-1\right\} \times 10^{3},
$$

where $X$ is ${ }^{13} \mathrm{C}$ or ${ }^{15} \mathrm{~N}$ and $R$ is the isotope ratio of ${ }^{13} \mathrm{C} /{ }^{12} \mathrm{C}$ and ${ }^{15} \mathrm{~N} /{ }^{14} \mathrm{~N}$ of the sample and standard, respectively. The experimental precisions (based on the standard deviations of replicate analyses of glycine and alanine standards) were $>0.2 \%$ for $\delta^{13} \mathrm{C}$ and $\delta^{15} \mathrm{~N}$.

2.6. Data Analysis. To analyze the species composition at each site, the numerical abundances of prey species per $R$. clavigera individual were subjected to Ryan's multiple comparison. When a species was significantly more abundant than the others occurring at a site, we defined it as the dominant species.

We analyzed the data from the predation experiment and the prey choice test by performing a $t$-test for each pair of prey items to determine the preferred prey for each prey combination. The prey preferences of $R$. clavigera were subsequently ranked. The species were assigned the same rank, when there was no significant difference in preference between two prey species.

\section{Results}

3.1. Species Composition. The numerical abundances of each prey per $R$. clavigera at each site (mean $\pm \mathrm{SD}$ ) were as follows: Nabeta: T. japonica, $3.21 \pm 3.69$; C. mitella, 2.36 \pm 3.05 ; Mytilus galloprovincialis, $2.81 \pm 3.05$; Shirahama: T. japonica, $57.59 \pm$ 159.05; C. mitella, 8.12 \pm 24.22 ; M. galloprovincialis, $0.32 \pm 0.66$; and Suzaki: T. japonica, $0.25 \pm 0.71$; C. mitella, $0.63 \pm 1.77$; Arcuatula senhousia, $0.74 \pm 1.14$. Ryan's multiple comparison revealed that $T$. japonica was the dominant prey species at Shirahama $(P<0.05)$, but no significantly dominant prey species occurred at Nabeta or Suzaki.

3.2. Predation Experiment. The predation preference ranks of $R$. clavigera are shown in Table 1 . At Nabeta, C. mitella was preferred over $S$. virgatus $(t$-test, $P<0.05)$ and $T$. japonica $(t$ test, $P<0.05)$, and T. japonica was preferred over $S$. virgatus $(t$-test, $P<0.05)$. On the basis of these predation rates, we speculated that the prey preferences of $R$. clavigera in Nabeta were in the following order: C. mitella $>$ T. japonica $>S$. virgatus (Table 1). At Shirahama, C. mitella was preferred over $S$. virgatus ( $t$-test, $P<0.05$ ), and $T$. japonica was preferred over $S$. virgatus ( $t$-test, $P<0.05)$. However, there was no significant difference between the predation rate for $C$. mitella and T. japonica ( $t$-test, $P>0.05$ ). Accordingly, the prey preference ranks for $R$. clavigera in Shirahama were C. mitella $=T$. japonica $>$ S. virgatus (Table 1). At Suzaki, C. mitella was preferred over A. senhousia ( $t$-test, $P<0.05$ ), C. mitella was preferred over T. japonica ( $t$-test, $P<0.05$ ), and A. senhousia was preferred over T. japonica $(t$-test, $P<0.05)$. Thus, the predatory preference ranks were C. mitella $>$ A. senhousia $>$ T. japonica (Table 1).

At all the sites, C. mitella was the preferred prey item for $R$. clavigera; however, T. japonica was equally preferred in Shirahama (Table 1).

3.3. Prey Choice Test. The ranked prey choices of $R$. clavigera are shown in Table 1. In the tests performed using live prey, at Nabeta $S$. virgatus was preferred over C. mitella ( $t$-test, 
$P<0.05)$, S. virgatus was preferred over T. japonica ( $t$-test, $P<0.05)$, and C. mitella was preferred over T. japonica ( $t$ test, $P<0.05)$. These results suggested that the live prey choices in Nabeta were ranked as follows: $S$. virgatus $>C$. mitella $>$ T. japonica. In Shirahama, S. virgatus was preferred over C. mitella ( $t$-test, $P<0.05)$, and T. japonica was preferred over $C$. mitella ( $t$-test, $P<0.05$ ). However, there was no significant difference between the choice rates for $S$. virgatus and T. japonica ( $t$-test, $P>0.05)$. Therefore, the live prey choice in Shirahama was in the following order: $S$. virgatus $=$ T. japonica $>C$. mitella. In Suzaki, A. senhousia was preferred over T. japonica ( $t$-test, $P<0.05$ ), A. senhousia was preferred over $C$. mitella ( $t$-test, $P<0.05$ ), and T. japonica was preferred over $C$. mitella ( $t$-test, $P<0.05)$ resulting in a ranking of $A$. senhousia $>$ T. japonica $>C$. mitella.

When dead prey was used, in Nabeta, C. mitella was preferred over $S$. virgatus ( $t$-test, $P<0.05)$, C. mitella was preferred over $T$. japonica ( $t$-test, $P<0.05)$, and $T$. japonica was preferred over $S$. virgatus $(t$-test, $P<0.05)$. Thus, the dead prey choices in Nabeta were ranked as follows: C. mitella $>$ T. japonica $>$ S. virgatus. At Shirahama, T. japonica was preferred over $S$. virgatus ( $t$-test, $P<0.05$ ), and $C$. mitella was preferred over $S$. virgatus ( $t$-test, $P<0.05$ ). There was no significant difference between the choice rate for $C$. mitella and T. japonica. Thus, the dead prey preference for R. clavigera in Shirahama was ranked as C. mitella $=$ T. japonica $>$ $S$. virgatus. At Suzaki, T. japonica was preferred over $A$. senhousia ( $t$-test, $P<0.05$ ), and $C$. mitella was preferred over A. senhousia ( $t$-test, $P<0.05$ ). There was no significant difference between the choice rate for $C$. mitella and $T$. japonica. Thus, the dead prey preference for $R$. clavigera in Suzaki was ranked as $C$. mitella $=T$. japonica $>$ A. senhousia .

In general, mussels were the most preferred prey item in the trials performed using live prey, and C. mitella was the most preferred prey item in the trials performed using dead prey. However, T. japonica was equally preferred to mussels and C. mitella in Shirahama (in dead and live prey trials, resp.) and to C. mitella in Suzaki (in dead prey trials).

3.4. Stable Isotope Analysis. The carbon and nitrogen stable isotope ratios of the prey species and $R$. clavigera are shown in Figure 2. The nitrogen stable isotope ratios of Mytilidae species were $2.5 \%$ to $3.9 \%$ lower than those of $R$. clavigera, whereas those of T. japonica and C. mitella showed similar values to those of $R$. clavigera. The carbon stable isotope ratios of Mytilidae species were $0.7 \%$ to $2.0 \%$ lower than those of R. clavigera, and those of T. japonica and C. mitella were $1.6 \%$ to $5.0 \%$ and $2.3 \%$ to $5.2 \%$ lower, respectively, than those of R. clavigera.

\section{Discussion}

The state of prey (i.e., alive or dead) had a greater effect on $R$. clavigera preference than the experimental approach used (i.e., predation experiment or prey choice test). Both experiments performed using dead prey indicated C. mitella was the most preferred prey item, whereas the prey choice test performed using live prey ranked mussels as the most preferred prey item. These results indicate the following two possibilities. First, the result of prey choice tests could accurately reflect predation preference. The prey choice test determined the predator's preference for prey on the basis of orientation, but not the act of predation itself. However, the similarity of results between the predation and prey choice tests performed using dead prey (Table 1) suggests that the results of prey choice tests might not differ significantly from those of predation experiments. Second, the choice test performed using live prey could be a useful alternative to standard predation experiments. $R$. clavigera pierces the prey's shell and dissolves its tissue for consumption [11, 12]. Thus, there is a cost associated with drilling when feeding on live organisms, but not on dead items. Because of the low predation cost, predation experiments and prey choice tests performed using dead prey are not suitable for accurately determining the prey preference of $R$. clavigera.

The results of the carbon and nitrogen stable isotope analyses support this point of view. The carbon, but not nitrogen, stable isotope values for $R$. clavigera and Mytilidae species were similar (Figure 2). Generally, a consistent difference in isotope fractions is found between a consumer and its food source. Low or negligible $\delta^{13} \mathrm{C}$ enrichment (approximately $1 \% 0$ ) has been found to occur $[13,14]$, but a higher fractionation (approximately 3.4\%) is usually assumed for $\delta^{15} \mathrm{~N}$ [15]. Thus, our results suggested that $R$. clavigera consumes large quantities of mussels. Taken together, the finding of these analyses and the fact that Mytilidae species were not the dominant species at any of study sites suggest that $R$. clavigera tend to selectively predate Mytilidae species. The carbon and nitrogen stable isotope methods seem to be effective for investigating the prey preference of $R$. clavigera when combined with the species composition data.

Considering the point of view of anthropogenic impacts on the communities studied, we can identify the most benign experimental method. The prey choice test needed only five individuals of each prey species from each site (in total, 45 individuals), and all the individuals were returned to their habitats. In contrast, prey items were destroyed during the stable isotope analysis. Thus, the choice test would seem the most ecologically benign method. Moreover, the carbon and nitrogen stable isotope analyses were time consuming and costly. Therefore, the prey choice test is beneficial in terms of the reduced species impacts, financial costs, and experimental time.

The prey choice method could be used to determine the prey preferences of muricid snails. For example, since, in the choice test, many target predators can be maintained in a starvation state during the experiments, many replicate trials can be conducted within a short time. In addition, this method might be suitable for determining the food preference of carnivores that prey on endangered species. The muricid snail Drupella cornus (Roding, 1798) is known to be a coral predator that is attracted to its prey by chemical cues [16]. The prey choice test could be used to determine the prey preferences of this snail without causing damage to endangered coral species. In conclusion, the prey choice test performed using live prey could be a useful method 


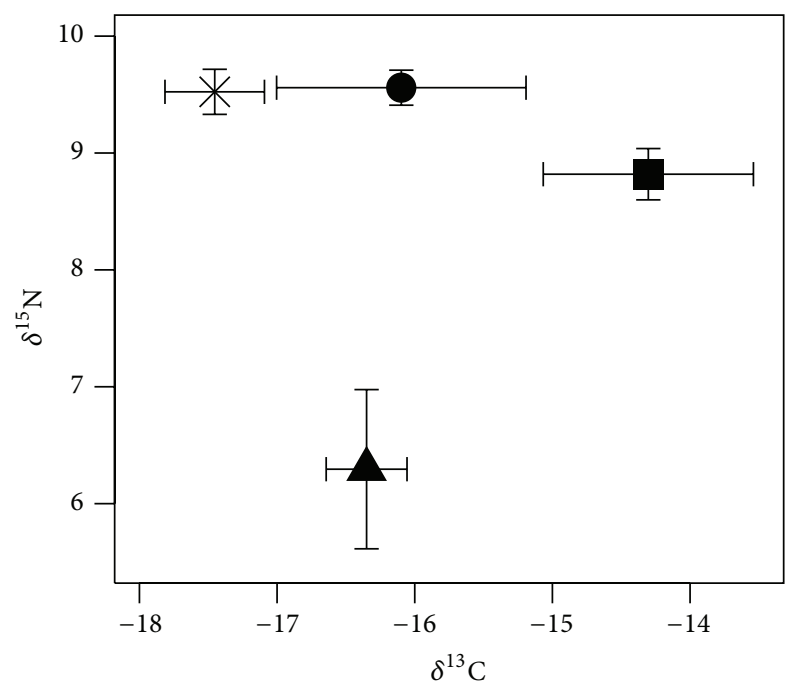

(a)

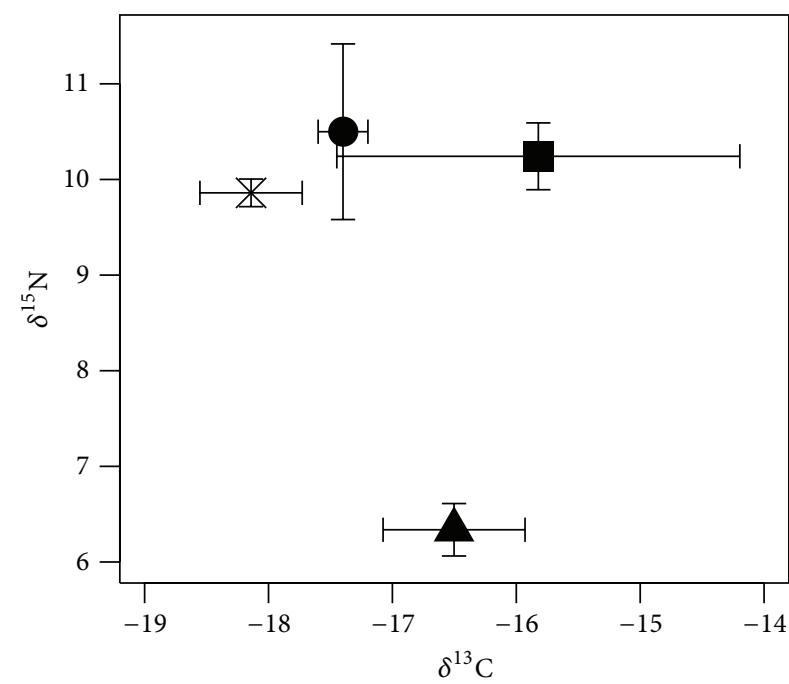

(b)

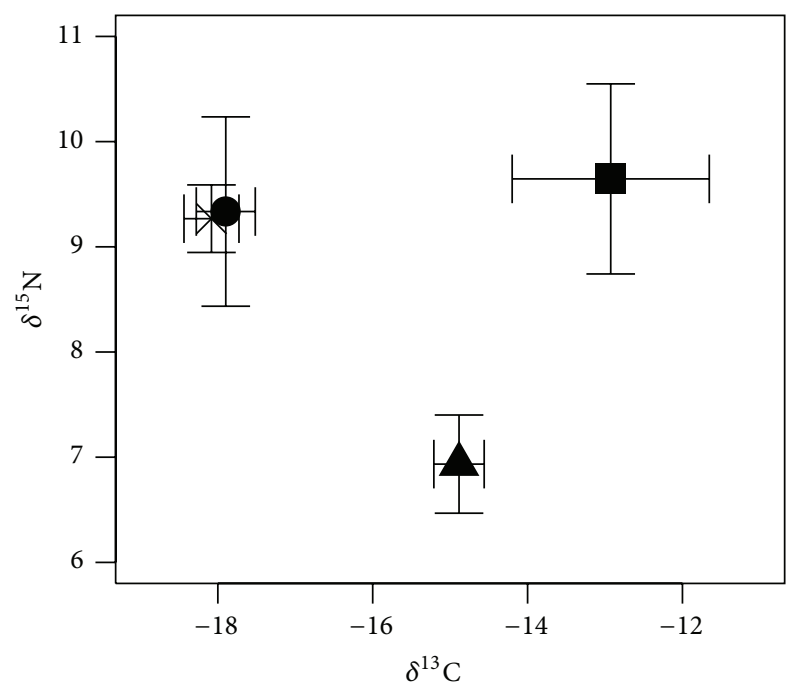

(c)

Figure 2: Mean $\delta^{13} \mathrm{C}$ and $\delta^{15} \mathrm{~N}$ ratios of prey and predator species from Nabeta (a), Shirahama (b), and Suzaki (c) $(n=5$ per each species). Triangle $=S$. virgatus in Nabeta (a) and Shirahama (b) and A. senhousia in Suzaki (c); $\times$ = Capitulum mitella; circle = Tetraclita japonica; and square $=$ Reishia clavigera . Error bars indicate 1 standard deviation .

for identifying prey preferences where collecting prey is technically difficult or ethically undesirable.

\section{Conclusions}

In the present study, we proposed the next best method to investigate the prey preference of the muricid snail, $R$. clavigera, of which live prey collection is difficult. The prey preference was usually investigated by the amount of predation; however, this method required considerable number of live prey. Our present study indicated that prey choice test that requires lesser number of prey items and depends on the chemical cues from prey items is the appropriate method for investigating the prey preference of muricid snails.

\section{Conflict of Interests}

The authors declare that there is no conflict of interests regarding the publication of this paper.

\section{Acknowledgments}

The authors are grateful to Dr. Kazunori Hasegawa of the National Museum of Nature and Science, for help with species identification. They thank the technical staff at the Shimoda Marine Research Center, University of Tsukuba, for support with sample collection and rearing. They also are indebted to Dr. Ken-ichi Hayashizaki of Kitasato University, for conducting the stable isotope analysis. The constructive 
comments on the paper by anonymous reviewers are considerably appreciated. This study was supported in part by a Grant-in-Aid for Young Scientists (B) and ESJ Chubu Grant in 2014.

\section{References}

[1] K. Arayama, "Experimental determination of the attributes of channel catfish prey," Nippon Suisan Gakkaishi, vol. 76, no. 1, pp. 68-70, 2010.

[2] K. Arayama and J. Iwasaki, "Recent problems on the invasive alien fish in Lake Kasumigaura, Ibaraki Prefecture: current states and reduction methods for channel catfish," Nippon Suisan Gakkaishi, vol. 78, no. 4, pp. 761-764, 2012.

[3] R. T. Paine, "Food web complexity and species diversity," The American Naturalist, vol. 100, pp. 65-75, 1966.

[4] L. K. Y. Tong, "The feeding ecology of Thais clavigera and Morula musiva (Gastropoda: Muricidae) in Hong Kong," Asian Marine Biology, vol. 3, pp. 163-178, 1986.

[5] N. Abe, "Growth and pray preference of the two forms in Thais clavigera (Küster) under rearing," Japanese Journal of Malacology, vol. 53, pp. 113-118, 1994.

[6] C. D. Stallings, "Experimental test of preference by a predatory fish for prey at different densities," Journal of Experimental Marine Biology and Ecology, vol. 389, no. 1-2, pp. 1-5, 2010.

[7] D. Savini and A. Occhipinti-Ambrogi, "Consumption rates and prey preference of the invasive gastropod Rapana venosa in the Northern Adriatic Sea," Helgoland Marine Research, vol. 60, no. 2, pp. 153-159, 2006.

[8] Y. Nakamura, T. Shibuno, D. Lecchini, and Y. Watanabe, "Habitat selection by emperor fish larvae," Aquatic Biology, vol. 6, no. 1-3, pp. 61-65, 2009.

[9] D. Lecchini, J. Shima, B. Banaigs, and R. Galzin, "Larval sensory abilities and mechanisms of habitat selection of a coral reef fish during settlement," Oecologia, vol. 143, no. 2, pp. 326-334, 2005.

[10] J. Spitz, T. Chouvelon, M. Cardinaud, C. Kostecki, and P. Lorance, "Prey preferences of adult sea bass Dicentrarchus labrax in the northeastern Atlantic: implications for bycatch of common dolphin Delphinus delphis," ICES Journal of Marine Science, vol. 70, no. 2, pp. 452-461, 2013.

[11] H. Fukumori, S. Y. Chee, and Y. Kano, "Drilling predation on neritid egg capsules by the muricid snail Reishia clavigera," Journal of Molluscan Studies, vol. 79, no. 2, pp. 139-146, 2013.

[12] D. C. P. Lau and K. M. Y. Leung, "Feeding physiology of the carnivorous gastropod Thais clavigera (Küster): do they eat 'soup'?" Journal of Experimental Marine Biology and Ecology, vol. 312, no. 1, pp. 43-66, 2004.

[13] M. J. Deniro and S. Epstein, "Influence of diet on the distribution of nitrogen isotopes in animals," Geochimica et Cosmochimica Acta, vol. 45, no. 3, pp. 341-351, 1981.

[14] M. Minagawa and E. Wada, "Stepwise enrichment of ${ }^{15} \mathrm{~N}$ along food chains: further evidence and the relation between $\delta 15 \mathrm{~N}$ and animal age," Geochimica et Cosmochimica Acta, vol. 48, no. 5, pp. 1135-1140, 1984.

[15] M. J. DeNiro and S. Epstein, "Influence of diet on the distribution of carbon isotopes in animals," Geochimica et Cosmochimica Acta, vol. 42, no. 5, pp. 495-506, 1978.

[16] M. Kita, M. Kitamura, T. Koyama et al., "Feeding attractants for the muricid gastropod Drupella cornus, a coral predator," Tetrahedron Letters, vol. 46, no. 49, pp. 8583-8585, 2005. 

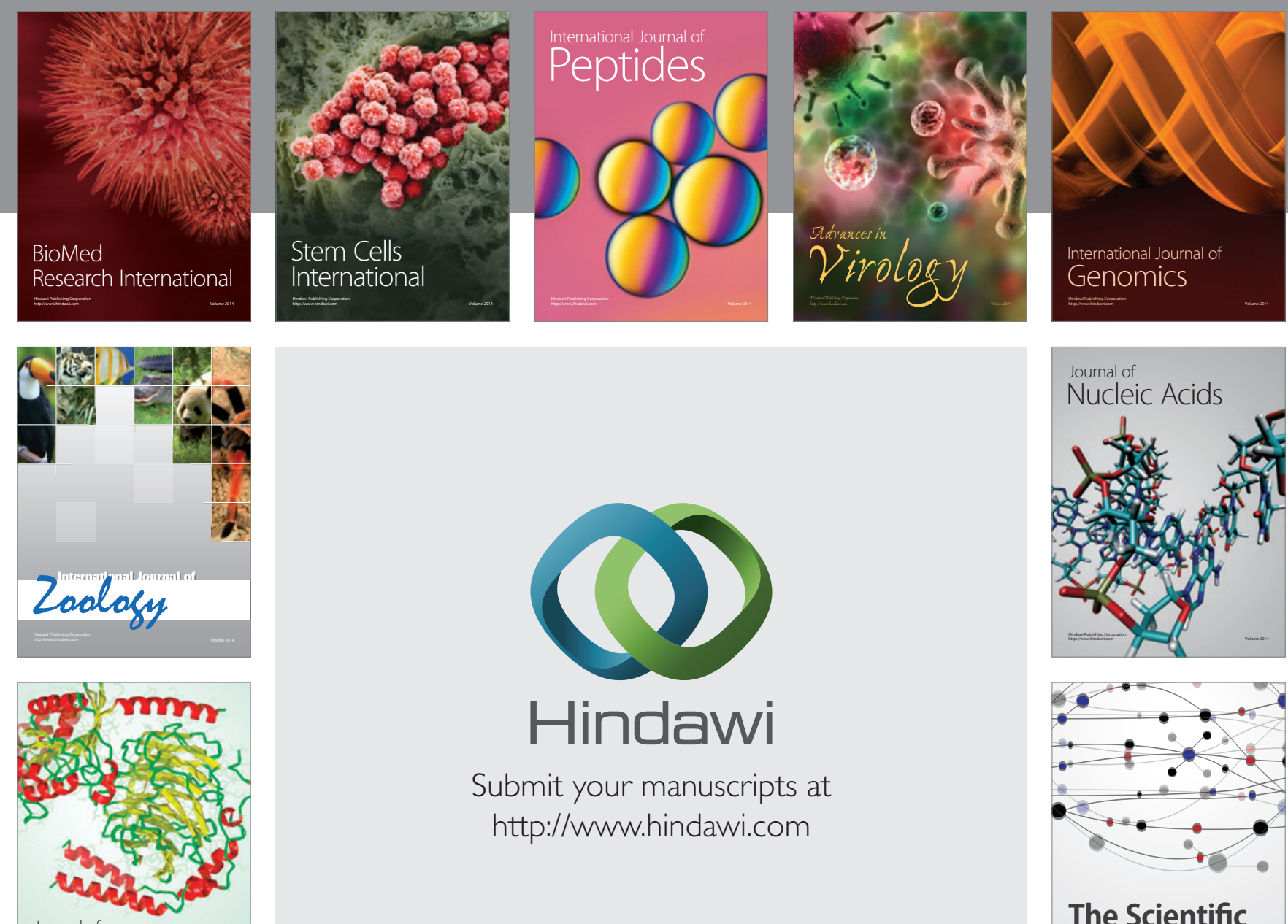

Submit your manuscripts at

http://www.hindawi.com

Journal of
Signal Transduction
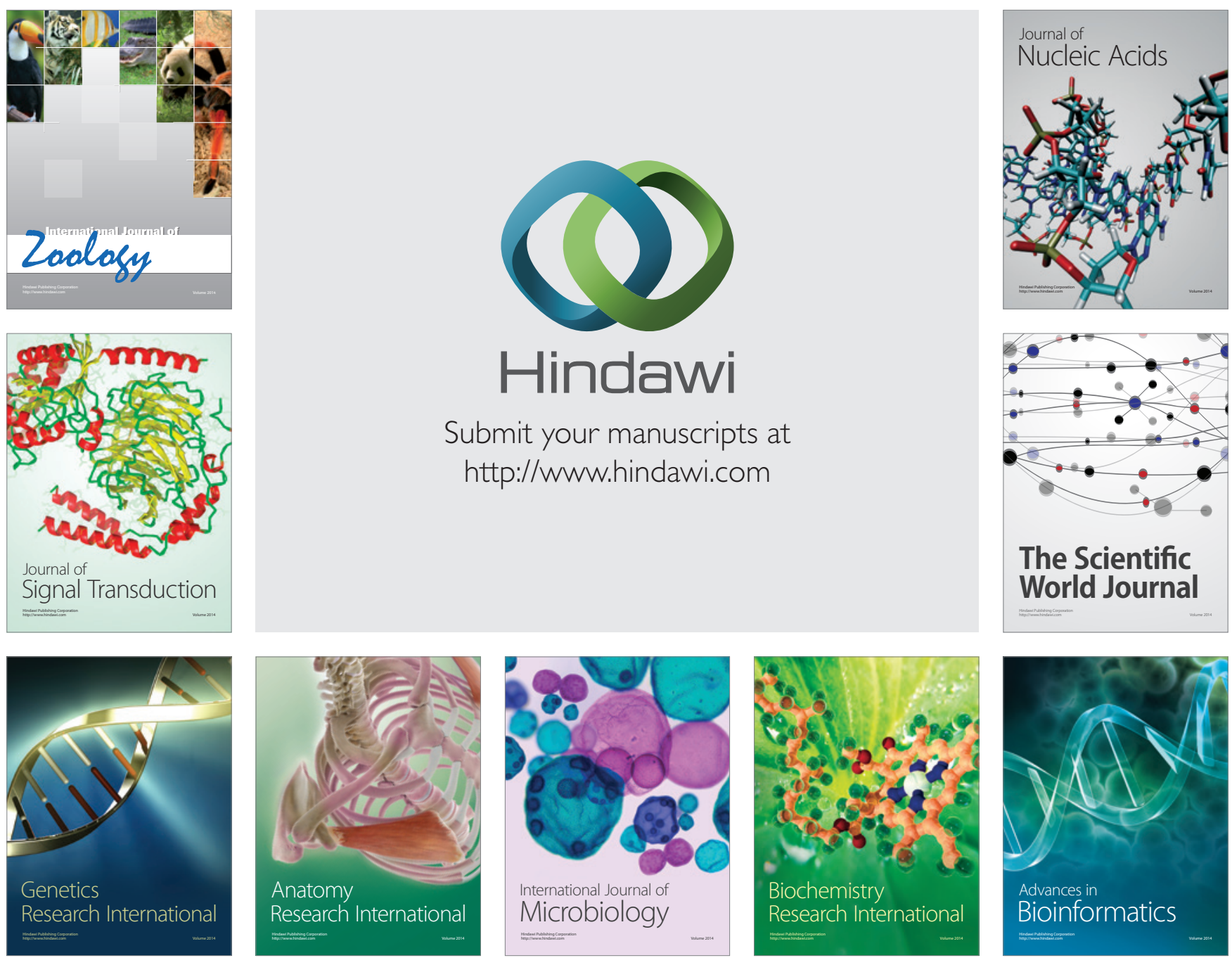

The Scientific World Journal
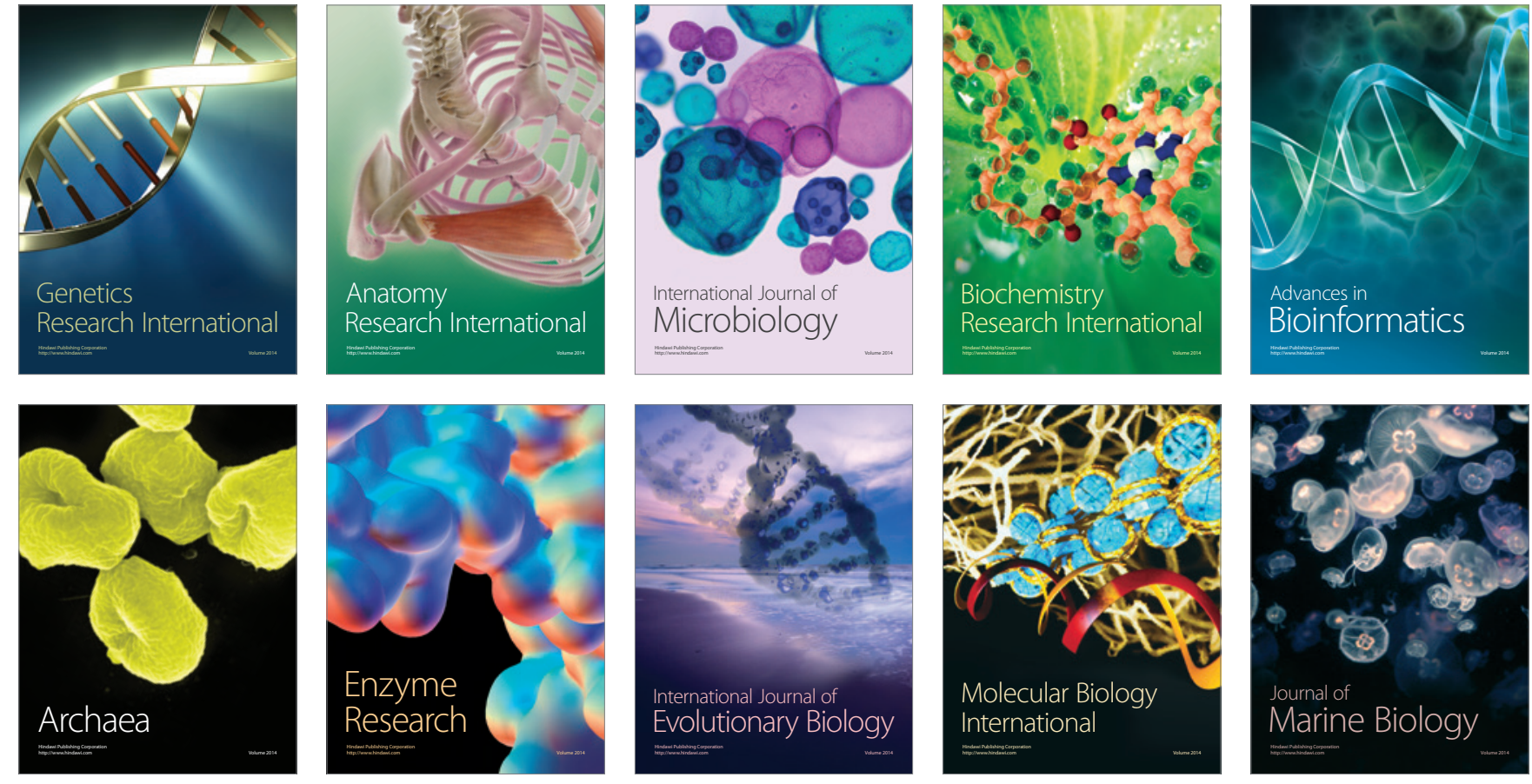